\title{
Call for Papers - Publication of Papers from ORIGINS 2014
}

OLEB will be publishing a special issue (or issues) of papers presented at ORIGINS 2014 (Nara, Japan, 6-11 July, 2014).

Manuscripts should be written following the style guidelines given under Instructions for Authors at http://www.springer.com/life+sciences/journal/11084.

As a general range for acceptable manuscript length, the Editors suggest a maximum of 4-8,000 words for talks and 2-4,000 words for posters. However, longer manuscripts may be considered in exceptional circumstances if the quality of the submission is outstanding and the reviewers feel that the length is justified.

As we anticipate there may be a heavy volume of response to this call, we would like to ask contributors to be willing to serve as reviewers for at least one other submission.

Please submit manuscripts to H.J. Cleaves (henderson.cleaves@gmail.com) before 1 November 2014.

A.W. Schwartz, H.J. Cleaves, J.P. Gogarten 